\title{
Free Recall Trial 1
}

National Cancer Institute

\section{Source}

National Cancer Institute. Free Recall Trial 1. NCI Thesaurus. Code C120402.

The first free recall task from the California Verbal Learning Test, second edition. 